IJBPAS, March, 2021, 10(3): 970-980

ISSN: 2277-4998

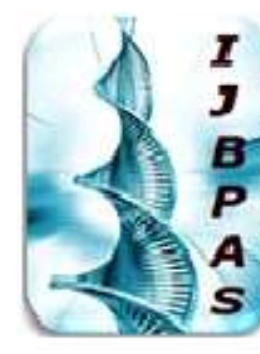

International Journal of Biology, Pharmacy and Allied Seiences (IJBPAS)

'A Bridge Betuen Caboratory and Q Qundo'

WwW.ijbpas.com

\title{
METHOD DEVELOPMENT, VALIDATION AND STABILITY INDICATING STUDY OF METHYLERGOMETRINE MALEATE USING RP-HPLC
}

\section{JADAV M ${ }^{1 *}$, PATEL $A^{2}$, JHA $L L^{3}$ AND ANAND $P^{4}$}

1: Department of Pharmaceutical Chemistry, School of Pharmacy, Parul University, P.O. Limda,

Ta. Waghodia - 391760, Gujarat, India

2: Department of Quality Assurance, Parul Institute of Pharmacy, Parul University, P.O. Limda,

Ta. Waghodia - 391760, Gujarat, India

3: Department of Pharmaceutics, School of Pharmacy, Parul University, P.O. Limda, Ta.

Waghodia - 391760, Gujarat, India

4: Department of Pharmacology, School of Pharmacy, Parul University, P.O. Limda, Ta.

Waghodia - 391760, Gujarat, India

*Corresponding Author: Manisha Jadav: E Mail: manisha.jadav121112@paruluniversity.ac.in

Received $15^{\text {th }}$ May 2020; Revised 12 ${ }^{\text {th }}$ June 2020; Accepted $17^{\text {th }}$ July 2020; Available online $1^{\text {st }}$ March 2021

https://doi.org/10.31032/IJBPAS/2021/10.3.5408

\section{ABSTRACT}

The aim of present study was to develop a simple, economical, precise and accurate RP-HPLC method along with its validation and to perform the stability indicating study for the estimation of methylergometrine maleate in formulation of injection. RP-HPLC method was developed by using Phenomenex Luna (c18 (2), 250 x $4.6 \mathrm{~mm}, 5 \mu$ ) and a combination of ammonium acetate: acetonitrile: in the ratio of 70:30 v/v as mobile phase, adjusted to $\mathrm{pH} 6.5$ by glacial acetic acid. The developed method was validated by showing the results of various validation parameters which are within the limits. Linearity ranges were $12-28 \mu \mathrm{g} / \mathrm{ml}$, correlation coefficient was 0.9979 and mean recovery was found to be $99.79 \%$. Further, stability indicating study has been performed and it showed positive results for acid degradation, alkali degradation, oxidation and sun-light exposure. Interferences of impurity peak were evaluated and found to be within limit. The developed method was found to be simple, sensitive, accurate and precise for analysis of 
$\overline{\text { methylergometrine maleate. The method can be adopted for analysis of drug in pharmaceutical }}$ dosage forms.

\section{Keywords: Stability, HPLC, Injectable, Degradation}

\section{INTRODUCTION}

Methylergometrine (MEM) is oxytocic drug indicated for the prevention and control of excessive bleeding following vaginal childbirth $[\mathbf{1}, \mathbf{2}]$. It is chemically 9, 10didehydro-N-[1-(hydroxymethyl)-propyl]-Dlysergamide. MEM acts directly on the smooth muscle of the uterus and increases the tone, and amplitude of rhythmic contractions through binding and the resultant antagonism of the dopamine $D_{1}$ receptor [3]. Thus, it induces a rapid tetanic uterotonic effect which shortens third stage of labour and reduces blood loss. Literature reveals many methods for the estimation of MEM that include HPLC with fluorescence, UV, LC-MS-MS, chromatographic and mass spectrometric methods [4-6]. Even metabolites of MEM in physiological specimens were estimated by capillary electrophoresis [7]. The bioavailability and pharmacokinetic of oral MEM in plasma was estimated by an automated pre-column: (OPS-2) coupled to liquid chromatography with photochemical degradation and electrochemical detection [8-11]. The objective of present study was to develop and validate a sensitive RP-HPLC based analytical method with a simple composition, low cost of mobile phase for determination of MEM and to evaluate stability indicating study in its parenteral dosage form.

Structure of MEM (Figure 1):

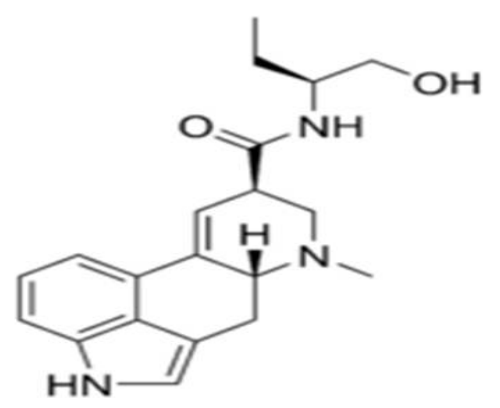

Figure 1: Structure of MEM

\section{MATERIALS AND METHODS:}

\subsection{Apparatus}

HPLC measurements were made on Shimadzu, (Class-VP Software), model 2489 series with UV detector and pneumatic pump.

\subsubsection{Reagents and solutions}

All chemicals and reagents were of analytical grade and solutions were prepared freshly with HPLC water. MEM sample was gifted by Mercury Lab, Vadodara, Gujarat.

\subsubsection{Chromatographic condition}

The analysis was performed by using HPLC instrument. The column used was Phenomenex Luna C 18 (2), 250 x 4.6 mm, 5 $\mu$. The mobile phase consisted of buffer 
(1.927 gm of ammonium acetate dissolved in $1000 \mathrm{ml}$ water and $\mathrm{pH}$ was adjusted to 6.5 ) and acetonitrile. It was filtered through membrane filter $(0.45 \mu)$, degassed and pumped from the solvent reservoir into the column in the ratio of $70: 30(v / v)$. The flow rate of mobile phase was maintained at 1.0 $\mathrm{ml} / \mathrm{min}$ and detection wavelength was set at $310.0 \mathrm{~nm}$ with a run time of $12 \mathrm{~min}$. The volume of injection loop was $20 \mu$. Prior to injection of the drug solution, the column was equilibrated for at least $30 \mathrm{~min}$ with the mobile phase flowing through the system. The column and the HPLC system were kept at ambient temperature.

\subsubsection{Preparation of standard stock} solution

Accurately weighed $49.6 \mathrm{mg}$ of MEM was transferred into the $50 \mathrm{ml}$ volumetric flask. $20 \mathrm{ml}$ of mobile phase was added, sonicated to dissolve and volume was diluted up to the mark and mixed well.

\subsubsection{Preparation of sample solution}

$2.5 \mathrm{ml}$ of Formulation was taken in $25 \mathrm{ml}$ volumetric flask. $10 \mathrm{ml}$ of diluent was added to this solution. The mixture was sonicated to dissolve the drug and finally the volume was made up to $25 \mathrm{ml}$ with HPLC grade water.

\subsubsection{Calibration curve}

Aliquots of standard stock solution (0.2 $\mathrm{mg} / \mathrm{ml}$ ) of MEM were taken into $10 \mathrm{ml}$ volumetric flasks separately and were diluted up to the mark with mobile phase to obtain the final concentration of 12,16, 20, 24 and $28 \mu \mathrm{g} / \mathrm{ml}$ of MEM. These solutions were injected into chromatographic system, chromatograms were obtained and peak area was determined for each concentration of drug solution. Prepared linearity plot of area Vs concentration and calculate the Yintercept, Y-intercept bias (at 100\% concentration level), slope of regression line, correlation co-efficient, $\mathrm{R}^{2}$ value and $\%$ relative standard deviation of response factor.

\subsubsection{Method Validation}

The proposed method was validated in terms of linearity, range, repeatability, method precision, intermediate precision, accuracy, LOD, LOQ, robustness, ruggedness and system suitability. 2.1.8 Linearity and range

The linearity of response for MEM was determined by preparing and injecting solutions with concentrations of $12 \mu \mathrm{g} / \mathrm{ml}$ to $28 \mu \mathrm{g} / \mathrm{ml}$.

\subsubsection{Repeatability}

Intraday and interday repeatability of the proposed method was determined on the API.

\subsubsection{0 (A) Intraday}

The solutions of three different concentrations viz. $12 \mu \mathrm{g} / \mathrm{ml}, 20 \mu \mathrm{g} / \mathrm{ml}$ and $28 \mu \mathrm{g} / \mathrm{ml}$ were prepared and six replicates of each were injected into HPLC system on the 
same day. The \% relative standard deviation was calculated.

\subsubsection{1 (B) Interday}

Fresh solutions of three different concentrations viz. $12 \mu \mathrm{g} / \mathrm{ml}, 20 \mu \mathrm{g} / \mathrm{ml}$ and $28 \mu \mathrm{g} / \mathrm{ml}$ were prepared and six replicates of each were injected into HPLC system on 3 consecutive days. The $\%$ relative standard deviation was calculated.

\subsubsection{Precision}

\subsubsection{Method Precision}

Six sample solutions of $20 \mu \mathrm{g} / \mathrm{ml}$ were prepared from the formulation and analysed by the proposed method to check the method precision.

\subsubsection{Intermediate precision (Interday)}

Three fresh sample solutions, each of 20 $\mu \mathrm{g} / \mathrm{ml}$, were prepared from the injection formulation and analysed on 3 consecutive days to check intermediate precision.

\subsubsection{Limit of Detection and Limit of Quantitation}

Limit of Detection (LOD) and limit of Quantitation (LOQ) for MEM was determined by visual method. In this, subsequent dilutions of different concentrations of MEM were prepared and injected into HPLC system. The limit of Quantitation (LOQ) was determined as the minimum concentration at which the $\% \mathrm{RSD}$ of three replicates were below $10.0 \%$. The limit of detection (LOD) was determined as the concentration at which the peak of MEM was detectable.

\subsubsection{Accuracy}

Accuracy (recovery) studies were performed by spiking MEM API in MEM injection at levels $80,90,100,110$ and $120 \%$ of label claim.

\subsubsection{Robustness}

Robustness of the method was determined by small, deliberate changes in flow rate, mobile phase ratio and $\mathrm{pH}$ of mobile phase. Flow rate was changed to $1.0 \pm 005 \mathrm{ml} / \mathrm{min}$. The mobile phase ratio was changed to $30 \pm 1 \%$ for acetonitrile. $\mathrm{pH}$ of mobile phase was changed to $6.5 \pm 0.1$.

\subsubsection{Ruggedness}

Method ruggedness was determined by analysing the sample at normal operating conditions and also by changing some of the operating analytical conditions such as column, instrument, analyst mobile phase composition and flow rate.

\subsection{Stability indicating study [12]}

\subsubsection{Forced degradation studies of MEM}

In order to establish stability-indicating nature of the method, pure MEM (API), and pharmaceutical formulation were subjected to various stress conditions to conduct forced degradation studies. Standard stock solution is used for forced degradation studies. Stress studies were carried out under the conditions of acid/base hydrolysis, oxidation, thermal, 
UV light as mentioned in ICH Q1A (R2) guideline.

\subsubsection{Preparation of acid induced degradation product}

$2.5 \mathrm{ml}$ of injection sample was accurately pipette out and transferred into the $25 \mathrm{ml}$ volumetric flask and sonicated to dissolve. 10 $\mathrm{ml}$ of diluent and $2 \mathrm{ml}$ of HCL (2M) were added to it and this solution was heated at $80^{\circ} \mathrm{C}$ for 60 minutes. After cooling at room temperature $\mathrm{pH}$ of the solution was adjusted to 7 with $2 \mathrm{ml} \mathrm{NaOH}(2 \mathrm{M})$. Then diluted up to the mark with diluent and mixed well.

\subsubsection{Preparation of base induced} degradation product

$2.5 \mathrm{ml}$ of injection sample accurately pipette out and transferred into the $25 \mathrm{ml}$ volumetric flask and sonicated to dissolve. $10 \mathrm{ml}$ of diluent and $2 \mathrm{ml}$ of $\mathrm{NaOH}(1 \mathrm{M})$ was added to it and this solution was heated at $80^{\circ} \mathrm{C}$ for 60 minutes. After cooling at room temperature $\mathrm{pH}$ of the solution was adjusted to 7 with 2 $\mathrm{ml}$ of HCL (1M). Then diluted up to the mark with diluent and mixed well. This solution was injected to HPLC.

\subsubsection{Preparation of $\mathrm{H}_{2} \mathrm{O}_{2}$ induced degradation product}

$2.5 \mathrm{ml}$ of injection sample accurately pipette out and transferred into the $25 \mathrm{ml}$ volumetric flask and sonicated to dissolve. $10 \mathrm{ml}$ of diluent and $5 \mathrm{ml}$ of $3 \% \mathrm{H}_{2} \mathrm{O}_{2}$ was added to it and this solution was heated at $80^{\circ} \mathrm{C}$ for 60 minutes. After cooling at room temperature it was diluted up to the mark with diluent and mixed well. This solution was injected to HPLC.

\subsubsection{Preparation of photo degradation product}

$1 \mathrm{ml}$ of injection sample accurately pipette out which was previously exposed to sunlight for 30 minutes and transferred into the $10 \mathrm{ml}$ volumetric flask. Afterwards, sufficient amount of diluent was added and solution was sonicated to dissolve it, then diluted up to the mark with diluent and mixed well. This solution was injected to HPLC.

\section{RESULTS \& DISCUSSION}

High Performance Liquid Chromatographic method was developed for the determination of MEM in Formulation .The conditions were optimized to obtain an adequate separation and detection of the eluted compound. Here various trials were taken based on the available literature to optimise HPLC conditions for method development of MEM in Formulation. For the selection of buffer various trials were taken using sodium citrate, sodium phosphate and ammonium acetate along with acetonitrile in different ratios. Various optimisations of buffer and acetonitrile were done and finally ammonium acetate; acetonitrile in the ratio of 70: 30 was selected because of high resolution and better peak purity. Then trials were taken with 
different HPLC columns like Phenomenex Luna C18 (2) $(250 \times 4.6 \mathrm{~mm}) 5 \mu$ and Cosmosil C18 (250x4.6mm) $5 \mu$ column. Out of these two, Phenomenex Luna C18 (2) $(250 \times 4.6 \mathrm{~mm}) 5 \mu$ was giving satisfactory results in terms of retention time, area, peak purity and theoretical plates. The $\lambda$ max of the MEM was also found by scanning in UV spectrophotometer in the range of $200 \mathrm{~nm}$ to $350 \mathrm{~nm}$ in different solvents like methanol, water, acetonitrile etc, and found to be 310 nm. Typical chromatogram of MEM is depicted in figure 2. This value is same as reported in the literature. From this we can conclude that the drug MEM remains stable in different solvents and does not show any change in its peak properties. The proposed method was found to be linear in the concentration range of 12 to $28 \mu \mathrm{g} / \mathrm{ml}$ with correlation coefficient $\left(\mathrm{r}^{2}\right)$ 0.9979, slope 130600 and intercept 33977 . The calibration curve is shown in figure 3 . The method was validated in terms of accuracy, precision, repeatability, LOD, LOQ, ruggedness, system suitability and the results are recorded in Table 1. [13, 14].

The results of interday and intraday precision (\% RSD less than 2), method precision and intermediate precision (Table 1) indicate that the proposed method is precise enough for the analysis of drug. For specificity, no peaks are detected at the retention time of MEM.
MEM peak and impurities peak in standard preparation and in assay preparation are spectrally pure [15]. The retention time of the peak obtained due to MEM in the assay preparations is correspond with that obtained from standard preparation. For accuracy, the $\%$ recovery at each level of MEM is between $99.0 \%$ to $100.0 \%$. RSD for $\%$ recovery at each level is less than $2.00 \%$.For precision, the $\%$ RSD of MEM was found to be less than $2 \%$.

For Robustness, during small changes in the method, the \% RSD of MEM was found to be less than $2 \%$. Limit of detection and limit of Quantitation were found to be $1.471 \mu \mathrm{g} / \mathrm{ml}$ and $4.4588 \mu \mathrm{g} / \mathrm{ml}$ respectively. Values of recovery $\pm \mathrm{SD}$ was found to be greater than $98.0 \%$ indicated that the proposed method is accurate for the analysis of drug. Thus, a simple reverse phase liquid chromatographic method has been developed and subsequently stability indication and validation for the formulation was carried out [16, 17]. Here we used mobile phase consisting of ammonium acetate buffer having $\mathrm{pH} \quad 6.5$ adjusted with glacial acetic acid solution. The column was used Phenomenex Luna C18 (2) $(250 \times 4.6 \mathrm{~mm}) 5 \mu$ with flow rate $1 \mathrm{ml} / \mathrm{min}$ using UV detection at $310 \mathrm{~nm}$. The retention time of MEM was found to be 6.123. For stability indication, drug is treated with $1 \%$ solutions of $\mathrm{HCL}, \mathrm{NaOH}$ and $3 \% \mathrm{H}_{2} \mathrm{O}_{2}$ at 80 
${ }^{\circ} \mathrm{C}$ were done and results are depicted in

Table 2 and Figure 1, 2. Here interference of impurity peak was evaluated. The RPHPLC method for MEM in its parenteral dosage forms is established as per the ICH guidelines. MEM is very important in treatment of contraction of the uterus muscle in pregnancy and also used in the treatment of the migraine. On detailed literature survey, it was found that though MEM have been analyzed by many methods but in order to have the further good data it was analysed by RP-HPLC method. The peak purity data of standard solution, test solution and spiked sample solution proved the specificity of the proposed method. The results of precision, $\%$ recovery and all other validation parameters are within acceptance criteria. The results of stability indicating study in acid, alkali, oxidation and sun-light degradation was also within the limits. Chromatographic peak purity results indicated the absence of coeluting peaks with the main peak of MEM, which demonstrated the specificity of assay method for estimation of MEM in presence of degradation products. The method was validated in terms of linearity, range, repeatability, precision, accuracy, LOD, LOQ, solution stability, specificity, ruggedness and system suitability.

Table 1: Summary of validation parameters for the proposed method

\begin{tabular}{|c|c|}
\hline Parameters & Result \\
\hline Linearity & $12-28 \mu \mathrm{m} / \mathrm{ml}$ \\
\hline Repeatability; Intraday precision & $\mathbf{0 . 7 6 \%}$ \\
\hline Interday Precision & $\mathbf{0 . 5 0} \%$ \\
\hline Method Precision & $\mathbf{1 0 0 . 0 4} \pm \mathbf{0 . 2 7}$ \\
\hline Intermediate Precision & $\mathbf{9 9 . 7 6} \pm \mathbf{0 . 5 0}$ \\
\hline Accuracy; 80\% & $100.3 \%$ \\
\hline $90 \%$ & $99.14 \%$ \\
\hline $100 \%$ & $99.54 \%$ \\
\hline $110 \%$ & $100.41 \%$ \\
\hline $120 \%$ & $100.51 \%$ \\
\hline Assay & $100.04 \%$ \\
\hline Limit of Detection & $1.471 \mu \mathrm{g} / \mathrm{ml}$ \\
\hline Limit of Quantitation & $4.4588 \mu \mathrm{g} / \mathrm{ml}$ \\
\hline
\end{tabular}

Table 2: Results of the Different Stability Indicating Studies

\begin{tabular}{|c|c|c|c|}
\hline Degradation study & Peak purity & Limit & Status \\
\hline Acid degradation & $\mathbf{0 . 9 9 9 9}$ & \multirow{2}{*}{ NLT 0.98 } & Pass \\
\hline Alkali degradation & $\mathbf{0 . 9 9 5 7}$ & & Pass \\
\hline Peroxide degradation & $\mathbf{0 . 9 8 1 9}$ & & Pass \\
\hline Sun light exposure & $\mathbf{0 . 9 9 6 3}$ & & Pass \\
\cline { 1 - 2 } & & & \\
\hline
\end{tabular}




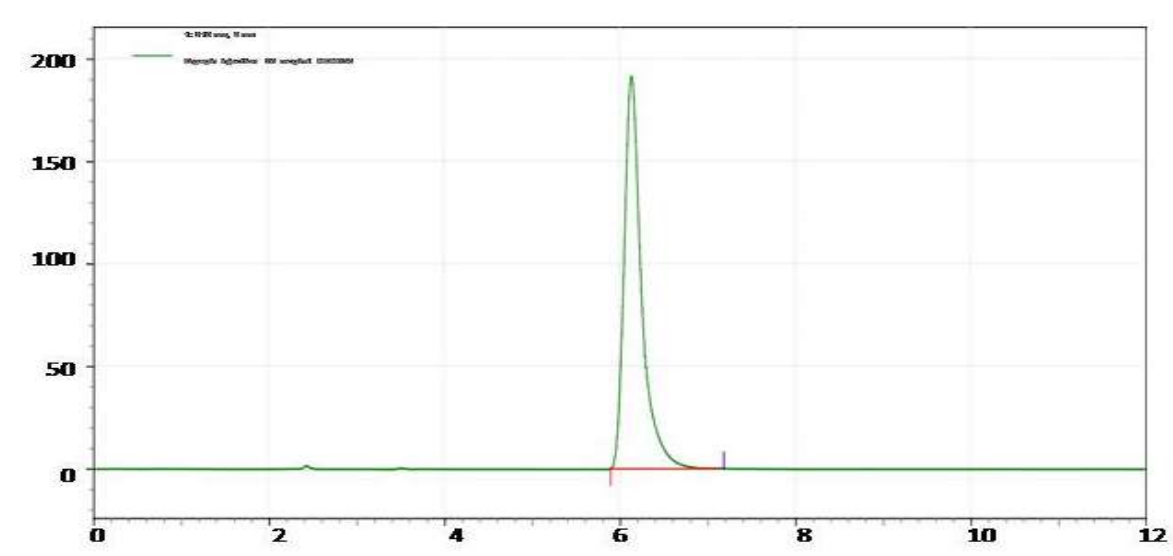

Figure 2: Development of Chromatogram for Methylergometrine

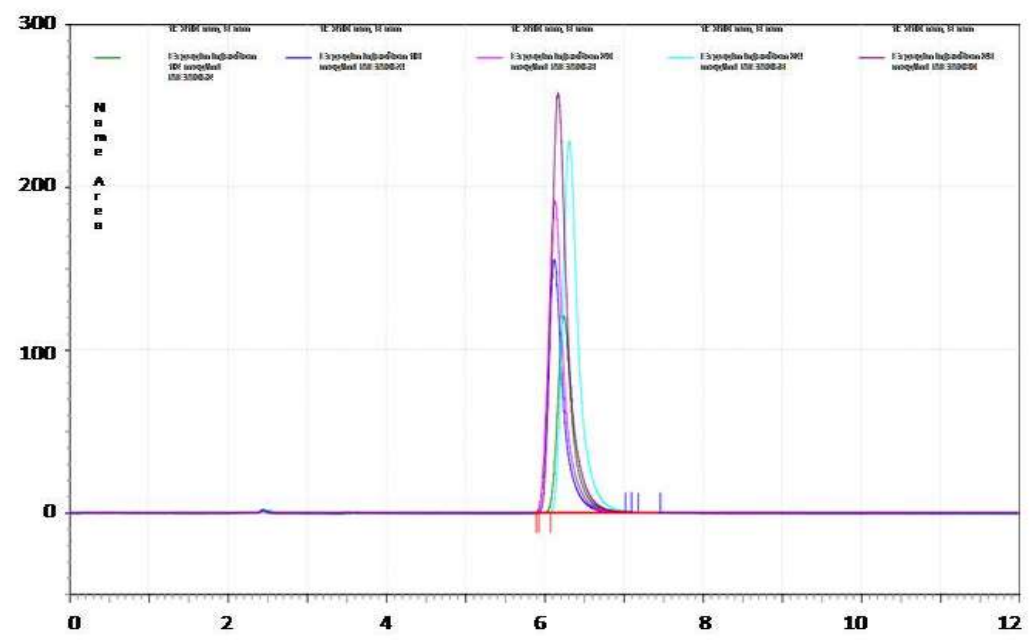

Figure 3: Linearity Overlay plot of Different Test Concentration

\section{CONCLUSION}

It may be concluded that developed method is simple, sensitive, rapid, linear, precise, rugged, accurate, and robust. Hence it is expected to be used for the routine analysis of MEM and may reveal potential utility of the proposed method for quality control laboratories.

\section{ACKNOWLEDGEMENTS}

The authors are thankful to Mercury Labotatories, Gorwa Vadodara, Gujarat, India for providing the gift sample of MEM and also providing facilities to carry out the work.

\section{REFERENCES}

[1] Amant F, Spitz B, Timmerman D, Coremans A and Van Assche FA, 
Misoprostol compared with methylergometrine for the prevention of postpartum haemorrhage; a double-blind randomised trial. BJOG; International Journal of Clinical Obstetrics and Gynaecology, 106 (10), (1999), 1066-1070.

[2] Singh G, Radhakrishnan, G, and Guleria K, Comparison of sublingual misoprostol, intravenous oxytocin, and intravenous methylergometrine in active management of the third stage of labor. International Journal of Clinical Obstetrics and Gynaecolog y 107(2), (2009), 130-134.

[3] Bredberg U, Eyjolfsdottir GS, Paalzow L, Tfelt-Hansen $\mathrm{P}$ and Tfelt-Hansen V, Pharmacokinetics of methysergide and its metabolite methylergometrine in man. European Journal of Clinical Pharmacoology 30(1), (1986), 7577.

[4] Frost M, Kohler H and Blaschke G, Determination of LSD in blood by capillary electrophoresis with laserinduced fluorescence detection. Journal of Chromatography B Biomedical Sciences and Applications 693(2), (1997), 313-319.
[5] Reuschel SA, Eades D and Foltz RL. Recent advances in chromatographic and mass spectrometric methods for determination of LSD and its metabolites in physiological specimens. Journal of Chromatography B Biomedical Sciences and Applications. 733(1-2), (1999), 145-159.

[6] Nakamichi T, Yawata A, Hojo H, Kagaya H, Kobayashi $S$ and Chikuma T, Monitoring of methylergometrine in human breast milk by solid-phase extraction and high-performance liquid chromategraphy with fluorimetric detection. Die Pharmazie - $A n$ International Journal of Pharmaceutical Sciences , 67(6), (2012), 482-484.

[7] de Groot ANJA, Vree TB, Hekster YA, Biggelaar-Martea $M$, van Dongen PWJ and Roosmalen JV, Pharmacokinetics and bioavailability of oral methylergometrine and ergometrine in male volunteers. Biopharmacetics \& Drug Disposition 15, (1996), 65-73.

[8] Allonen H, Juvakoski R, Kanto J, Laitinen S, Mantyla R and Kleimola $\mathrm{T}$, Methylergometrine; comparison of plasma concentrations and clinical 
response of two brands. International Journal of Clinical Pharmacology and Biopharmacy 16(7), (1978), 340-342.

[9] Mantyla R and Kanto J, Clinical pharmacokinetics of methylergometrine (methylergonovine). International Journal of Clinical Pharmacology, Therapy, and Toxicology 19(9), (1981), 386-391.

[10] Gao Y, Sun Q, Liu De, Ma B, Zhao $\mathrm{H}$,Fang $\mathrm{Z}$, Wang $\mathrm{H}$ and Lou $\mathrm{H}$, Sensitive LC-MS/MS method to quantify methylergonovine in human plasma and its application to a pharmacokinetic study. Journal of Chromatography B Analytical Technologies in the Biomedical and Life Sciences 101, (2016), 6268.

[11] Baldelli S, Cattaneo D, Pignatelli P, Perrone V, Pastori D, Radice S and Clementi E, Validation of an LC-MS/MS method for the simultaneous quantification of dabigatran, rivaroxaban and apixaban in human plasma. Bioanalysis 8, (2016), 275-283

[12] Marigny $\mathrm{K}$, Lohezic-Ledevehat F, Aubin F and Burgot G, Stability of oral liquid preparations of methylergometrine. Pharmazie 61, (2006), 701-705.
[13] Jain V and Sharma MC, Validated RP-HPLC method for determining the levels of bromhexine $\mathrm{HCl}$, chlorpheniramine maleate, dextromethorphan $\mathrm{HBr}$ and guaiphenesin in their pharmaceutical dosage forms. Journal of Taibah University for Science 10, (2016), 38-45.

[14] Kowalczyk, E Patyra, A Grelik and K Kwiatek, Development and validation of an analytical method for determination of ergot alkaloids in animal feeding stuffs with high performance liquid chromategraphy- fluorescence detection. Polish J. Veterinary Sciences 19, (2016) 559-565.

[15] Mantripragada MKV, Rao SV, Nutulapati VV and Mantena BP, Simultaneous determination of impurities of atazanavir and ritonavir in tablet dosage form by using reversed-phase ultra performance liquid chromategraphic method. Journal of Chromatographic Science, 56(3), (2018), 270-284.

[16] Khetre AB, Sinha PK, Damle MC and Mahendre R, Development and Validation of Stability Indicating RP-HPLC Method for Voriconazole. Indian Journal of 
Pharmaceutical Sciences 71(5), (2009), 509-514.

[17] Mohamed Rizk, Maha Mahmoud Abou El-Alamin and Mervat Isaac Moawad, Development and validation of second derivative and synchronous spectrofluorimetric methods for determination of oxytocin and ergometrine maleate in their combined formulation. European Journal of Chemistry 9 (3), (2018), 241-250. 